\title{
Distancia entre ápices radiculares y el piso del seno maxilar y su relación con el patrón esquelético facial
}

\section{Distance between root apices and the floor of the maxillary sinus and its relation to the skeletal pattern facial}

\begin{abstract}
Resumen
Objetivo. Determinar la distancia de los ápices radiculares de premolares y molares superiores al piso del seno maxilar y su relación con el patrón esquelético. Métodos. Estudio transversal que incluyó 75 casos pre-tratamiento ortodóntico de archivos de pacientes que asistieron al Posgrado de Ortodoncia de la Universidad Autónoma de Nayarit, México. Se determinó el patrón esquelético de los pacientes por medio de radiografías cefálicas laterales y de acuerdo a la clasificación de Angle se agruparon en Clase I, Clase II y Clase III. Se midieron, sobre cortes realizados con tomografía computarizada de haz cónico, las distancias entre los ápices de segundos premolares, primeros y segundos molares superiores y el piso del seno maxilar. Se utilizó el software Ez3DPlus Versión 1.2.6.0 (Vatech, Gyeonggi-do, Korea). Se realizó el análisis de los datos mediante la prueba de t de Student. Resultados. Se encontraron diferencias significativas entre el grupo de premolares de Clase II (Media= 1,33; Varianza= 3,43) y Clase III (Media= 3,26; Varianza= 15,53), ( $p=0,031)$. Conclusiones. Los resultados obtenidos en este estudio mostraron que el patrón esquelético no fue determinante en la distancia de los ápices radiculares de molares superiores al piso del seno maxilar, sin embargo las diferencias encontradas entre los segundos premolares de Clase II y Clase III sí pudieran deberse a esta variable.
\end{abstract}

Palabras clave: Ápices radicular; Seno maxilar; Tomografía computarizada de haz cónico; clasificación de Angle; Ortodoncia (fuente: DeCS BIREME).

\begin{abstract}
Objective. To determine the distance between root apices of premolars and upper molars to the floor of the maxillary sinus and their relationship with the skeletal pattern. Methods. A cross-sectional study that included 75 orthodontic pre-treatment cases from the files of patients who attended the Orthodontic Postgraduate Course at the Autonomous University of Nayarit, México. The skeletal pattern of the patients was determined through digital lateral cephalometric radiographs and according to the Angle classification they were grouped in Class I, Class II and Class III. The distances between the apices of the second premolars, first and second upper molars and the floor of the maxillary sinus were measured on cone beam CT scans. The software Ez3DPlus Version 1.2.6.0 (Vatech,
\end{abstract}

\section{Artículo Original}

Brenda Garcia-Rosas 1,a, Tania Macías-Villanueva 1,a,b, Rafael Rivas-Gutiérrez ${ }^{1, a, b, c}$, Saúl Aguilar-Orozco 1,d

${ }^{1}$ Universidad Autónoma de Nayarit, Facultad de Odontología, Postgrado de Ortodoncia, Tepic, México. ${ }^{a}$ Cirujano Dentista.

${ }^{b}$ Especialista en Ortodoncia.

'Maestría en Odontología.

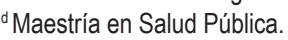

\section{Correspondencia:}

Brenda Garcia: brendalizeth.garciarosas@gmail.com Unidad Académica de Odontología, E7, Ciudad de la Cultura S/N,

63000 Tepic, Nayarit, México.

ORCID: 0000-0001-7984-6508

\section{Coautores:}

Tania Macias: maciasvillanuevataniagisela@gmail.com ORCID: 0000-0001-9642-2360

Rafael Rivas: rafarivas 8@hotmail.com ORCID: 0000-0001-5708-6827

Saul Aguilar: espodon2014@gmail.com ORCID: 0000-0002-2705-5760

\section{Editora:}

Luz Dahiana Alfaro Carballido

Universidad de San Martín de Porres. Lima, Perú.

Conflicto de intereses: los autores declaran no tener conflictos de interés.

Fuente de financiamiento: no fue requerida alguna fuente de financiamiento.

\section{Recibido: 16/11/19}

Aceptado: 01/01/20

Publicado: 09/05/20 
Gyeonggi-do, Korea) was used. Data analysis was performed using the Student t-test. Results. Significant differences were found between the Class II (Mean $=1.338$; $\mathrm{Sd}=1.852$ ) and Class III premolars group (Mean=3.26; $\mathrm{Sd}=3.941),(\mathrm{p}=0.031)$. Conclusions. The results obtained in this study showed that the skeletal pattern was not a determining factor in the distance of the root apices of upper molars to the floor of the maxillary sinus. However, the differences found between the second premolars of Class II and Class III could be due to this variable.

Keywords: Root apice; Maxillary sinus; Cone-beam computed tomography; Angle classification; Orthodontics (source: MeSH NLM).

\section{Introducción}

Los senos paranasales son prolongaciones aéreas de la cavidad nasal, formadas por los senos etmoidales, frontales, esfenoidales y maxilares. Desarrollan funciones biológicas de importancia como: aligerar el peso de la cabeza, humidificar y calentar el aire inhalado, aumentar la resonancia del habla, proporcionar un amortiguador contra el trauma facial y ayudar a la defensa inmunológica de la cavidad nasal ${ }^{1,2}$.

El seno maxilar o antro de Highmore es el nicho sinusal de mayor dimensión; comienza su formación a finales de la vida fetal y termina su desarrollo en la edad adulta, alcanzando una forma piramidal ${ }^{3,4}$

La pared inferior o piso del seno maxilar consiste en una fina placa ósea recubierta de una capa de mucosa que se encuentra en relación con los ápices radiculares del segundo premolar, primer molar y segundo molar. En ocasiones, el piso se extiende entre las raíces de los dientes, causando elevaciones en la superficie conocidas como "Hillocks" 3-5.

La proximidad de premolares y molares superiores a esta estructura anatómica es tomada en cuenta durante la planeación del movimiento ortodóntico ya que cuando las raíces dentales sobresalen hacia el seno maxilar, pueden ocasionarse reabsorción radicular apical moderada y mayor inclinación durante movimientos intrusivos u horizontales ${ }^{6}$.

Inicialmente, estas medidas eran realizadas en radiografías panorámicas, sin embargo se ha demostrado la poca fiabilidad de las imágenes bidimensionales en este tipo de evaluaciones al compararlas con las imágenes tomográficas de haz cónico ${ }^{7,8}$.

Algunos estudios han relacionado el tamaño de los senos maxilares con el patrón esquelético; Oktay ${ }^{9}$ encontró que éste puede ser mayor en las mujeres que presentan maloclusión Clase II, mientras que en el estudio realizado por Emami et al. ${ }^{10}$ observaron que las dimensiones y la superficie de los senos maxilares en la maloclusión esquelética de Clase III fueron mayores. Estos hallazgos sugieren que la cercanía de los ápices radiculares de los dientes superiores con el seno maxilar podría variar de acuerdo con el patrón esquelético. Establecer la relación entre la cercanía de los ápices radiculares de dientes posteriores al seno maxilar y el patrón esquelético, podría beneficiar al ortodoncista en la tarea de descartar y planear las mecánicas a utilizar en un patrón específico, por esta razón, el objetivo del presente estudio fue determinar la distancia desde los ápices radiculares de segundos premolares, primeros y segundos molares superiores hacia el piso del seno maxilar y su relación con el patrón esquelético.

\section{Métodos}

Este estudio fue aprobado por el Comité de Ética en Investigación de la Facultad de Odontología de la Universidad Autónoma de Nayarit. Ninguna persona estuvo expuesta a radiación para los fines de esta investigación; todas las imágenes radiográficas y tomográficas utilizadas formaban parte del archivo existente y se conservó el anonimato de los pacientes.

Se llevó a cabo un estudio transversal en el que, de acuerdo al criterio de inclusión, se requerían datos tomados de radiografías cefálicas laterales y tomografías computarizadas de haz cónico obtenidas de pacientes que concurrieron a la clínica del Posgrado en Ortodoncia de la Universidad Autónoma de Nayarit antes de realizar el tratamiento ortodóntico. Se incluyeron imágenes radiográficas que presentaban segundos molares superiores erupcionados con ápices cerrados, edad de 12 a 35 años y ausencia de enfermedades sistémicas. Las imágenes que presentaban ausencia de piezas dentarias posteriores superiores fueron excluidas de la muestra. Estos casos debían además contar con tomografía.

La muestra inicial estuvo conformada por 116 casos, sin embargo, durante la evaluación de las tomografías, se excluyeron del estudio aquéllos que mostraron falta de formación radicular en alguna de las piezas dentarias posteriores superiores, pacientes con segundos premolares de dos raíces y los que presentaban alteraciones en el seno maxilar, resultando una muestra de 94 casos.

En las radiografías cefálicas laterales se determinó el patrón esquelético sagital midiendo manualmente el ángulo ANB formado por los planos cefalométricos $\mathrm{Na}$ sion-punto A y Nasion-punto B. Cuando el valor de este ángulo era de $2^{\circ} \pm 2$ se clasificó como Clase I, cuando era mayor a $4^{\circ}$ como clase II y cuando era menor a $0^{\circ}$ como Clase III. La muestra quedó dividida en tres grupos integrados como se indica a continuación: Clase I= 31, Clase II $=38$ y Clase III $=25$.

Debido a que el número de integrantes en el grupo de Clase III era menor que en los otros grupos, se decidió igualarlos, eliminando al azar elementos de los grupos 
Clase I y II, para finalmente obtener tres grupos con 25 casos cada uno.

Las mediciones fueron realizadas por un mismo investigador utilizando el software Ez3DPlus versión 1.2.6.0 (Vatech, Gyeonggi-do, Korea). Cada caso fue medido tres veces para corroborar la veracidad de los datos obtenidos y sólo se midieron diez por día para evitar la fatiga ocular.

En las tomografías se tomó como referencia el plano palatino (ENA-ENP) (Figura 1). Se ubicaron en los cortes axiales los ápices de las raíces de los segundos premolares superiores, y de los primeros y segundos molares superiores (Figura 2). La distancia entre los ápices y el piso del seno maxilar se midió en forma lineal y perpendicular al plano palatino en los cortes coronal y sagital (Figuras 3 y 4). Este protocolo se llevó a cabo en cada una de las raíces de las piezas dentarias a evaluar, tanto en el lado izquierdo como en el lado derecho. Cuando los ápices radiculares sobrepasaban el piso del seno maxilar se consideraron con valores negativos $(-)$ y positivos $(+)$ cuando no alcanzaron esta estructura.

Análisis estadístico. Los datos obtenidos se tabularon en el programa Microsoft Excel 2013, teniendo en cuenta el órgano dentario y patrón esquelético sagital.

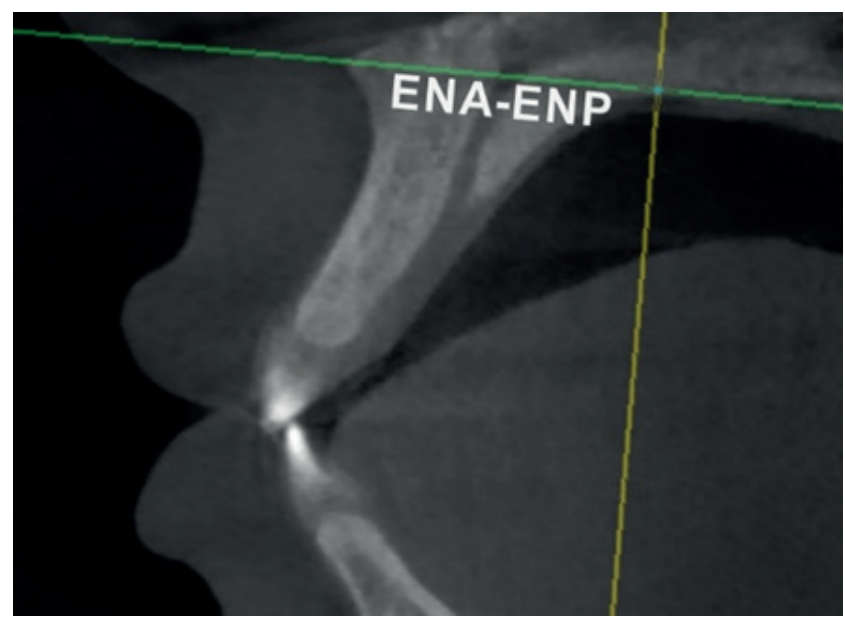

Figura 1. Imagen que muestra la determinación del plano palatino (ENA-ENP)

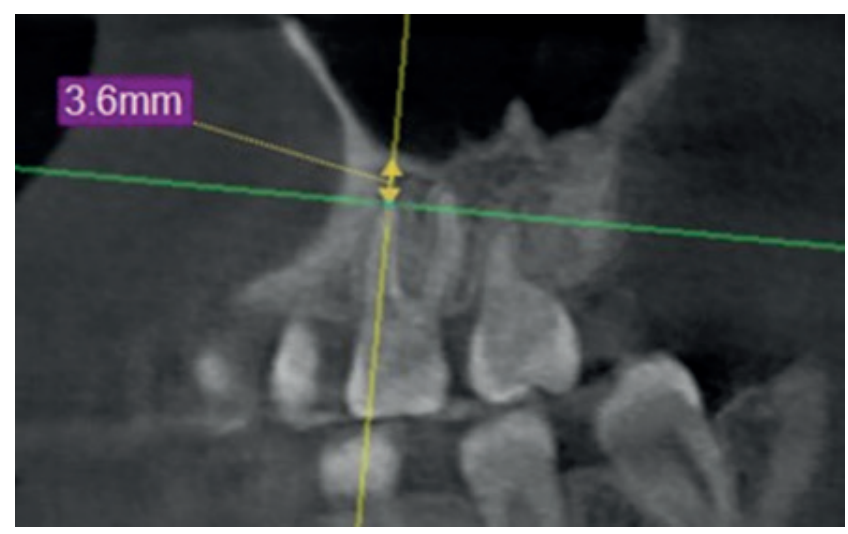

Figura 3. Medición lineal y perpendicular al plano palatino en la vista sagital
Con el fin de obtener un dato para cada tipo de órgano dentario se obtuvieron las medias aritméticas para segundo premolar, primer y segundo molar, incluyendo las medidas obtenidas en cada uno de los cortes (coronal y sagital), en cada una de las raíces y en ambos lados. De esta forma, se obtuvieron finalmente tres datos por paciente. Estos valores se compararon entre los distintos patrones esqueléticos a través de la prueba de t de Student para dos muestras, con un nivel de significancia de $\mathrm{p}<0,05$.

\section{Resultados}

De los 75 casos, divididos en 25 por cada clase esquelética, se analizaron un total de 450 dientes (150 segundos premolares, 150 primero molares y 150 segundos molares), distribuidos equitativamente entre los lados derecho e izquierdo. La distribución de éstos de acuerdo a su edad y sexo se muestra en la Tabla 1.

Los resultados fueron organizados por órgano dentario y se muestran en las Tablas 2, 3 y 4 . De acuerdo a las medias obtenidas, la pieza dentaria que mostró la relación más estrecha con el piso del seno maxilar fue el primer molar superior (Tablas 3 y Figura 5) aunque, al relacionarlas con la clase esquelética sagital, sólo se encontraron diferencias

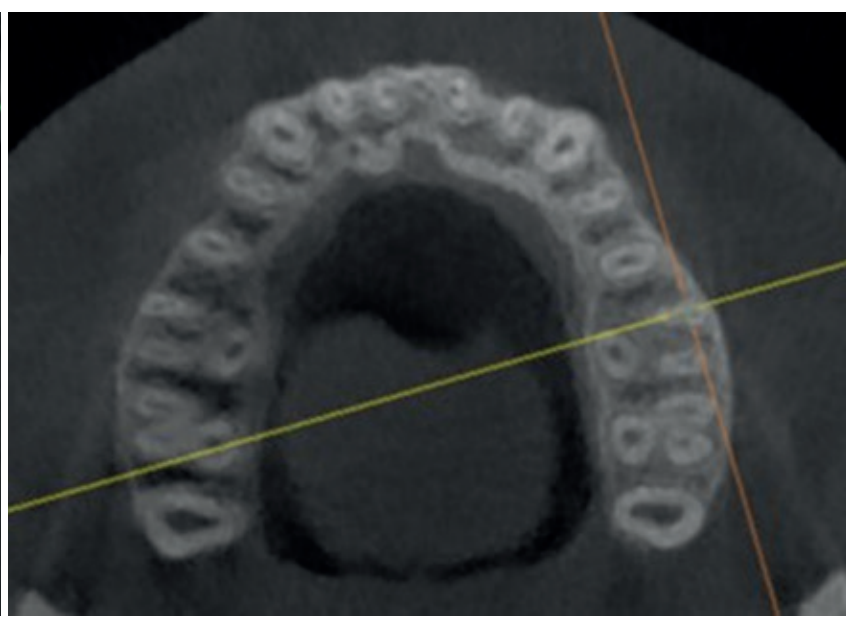

Figura 2. Ubicación de ápices radiculares en corte axial

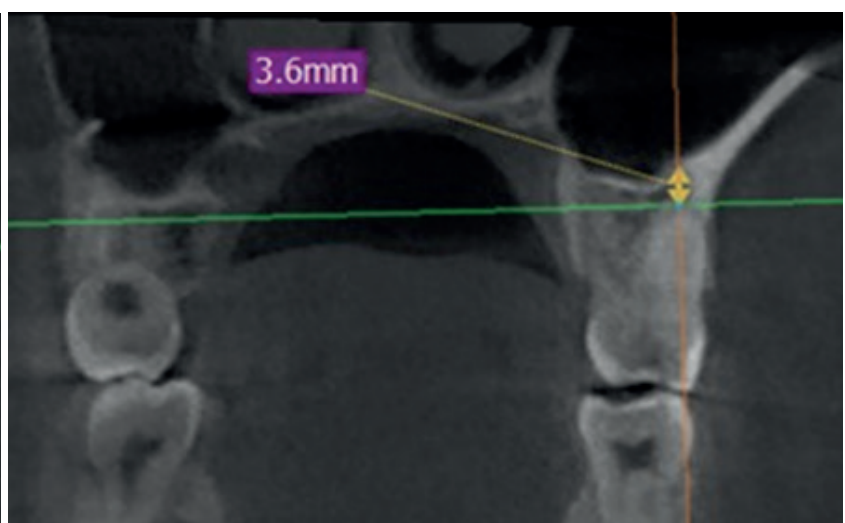

Figura 4. Medición lineal y perpendicular al plano palatino en la vista coronal 
Tabla 1. Distribución de casos por sexo, edad y patrón esquelético

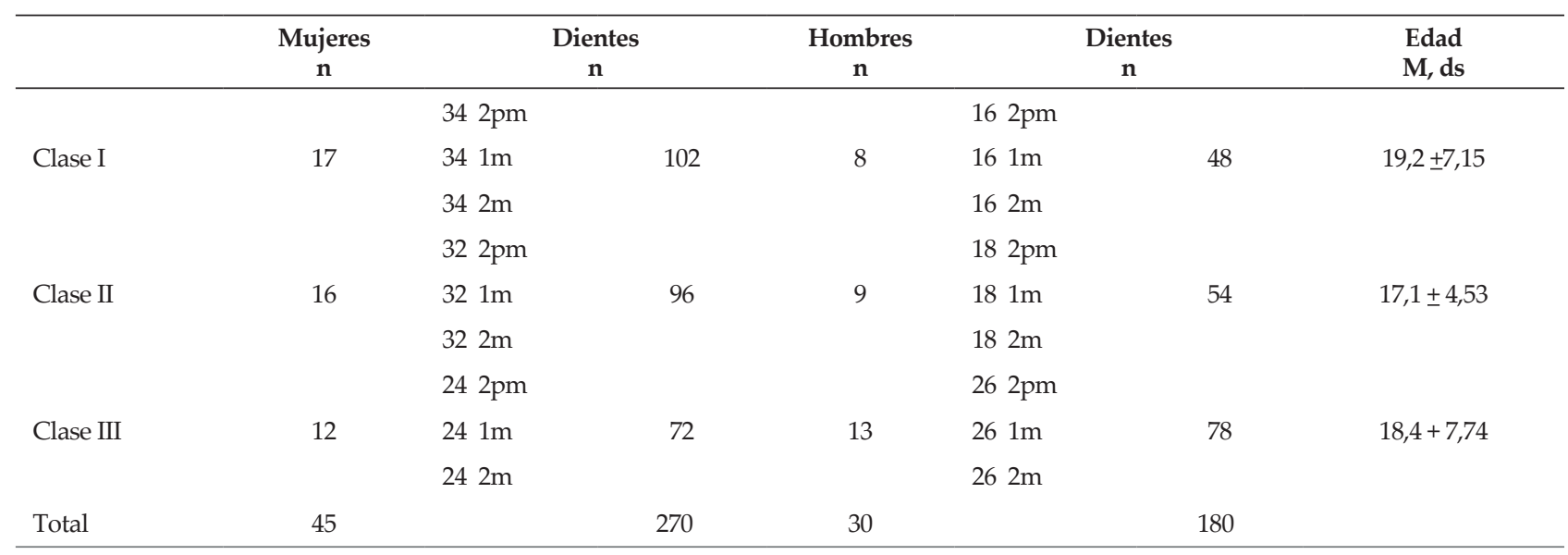

$\mathrm{n}$ : frecuencia; M: media; ds: desviación estándar; 2pm, 1m, 2m: segundo molar, primer molar, segundo molar.

Tabla 2. Distancias en milímetros entre los ápices radiculares de segundos premolares y el piso del seno maxilar y su comparación entre los patrones esqueléticos

\begin{tabular}{|c|c|c|c|c|c|c|}
\hline Patrón esquelético & Clase I & Clase II & Clase I & Clase III & Clase II & Clase III \\
\hline Media & 1,938 & 1,338 & 1,938 & 3,268 & 1,338 & 3,268 \\
\hline Desviación estándar & 2,880 & 1,852 & 2,880 & 3,941 & 1,852 & 3,941 \\
\hline Valor de $\mathrm{t}$ & \multicolumn{2}{|c|}{0,876} & \multicolumn{2}{|c|}{$-1,362$} & \multicolumn{2}{|c|}{$-2,216$} \\
\hline Valor de $\mathrm{p}$ & \multicolumn{2}{|c|}{0,385} & \multicolumn{2}{|c|}{0,179} & \multicolumn{2}{|c|}{$0,031^{*}$} \\
\hline
\end{tabular}

*Diferencia significativa entre clase II y clase III $p \leq 0,05$

Tabla 3. Distancias en milímetros entre los ápices radiculares de primeros molares y el piso del seno maxilar y su comparación entre los patrones esqueléticos

\begin{tabular}{|c|c|c|c|c|c|c|}
\hline Patrón esquelético & Clase I & Clase II & Clase I & Clase III & Clase II & Clase III \\
\hline Media & $-0,303$ & $-0,157$ & $-0,303$ & 0,090 & $-0,157$ & 0,090 \\
\hline Desviación estándar & 1,702 & 1,4382 & 1,702 & 2,340 & 1,438 & 2,340 \\
\hline Valor de $\mathrm{t}$ & \multicolumn{2}{|c|}{$-0,327$} & \multicolumn{2}{|c|}{$-0,680$} & \multicolumn{2}{|c|}{$-0,451$} \\
\hline Valor de $\mathrm{p}$ & \multicolumn{2}{|c|}{0,745} & \multicolumn{2}{|c|}{0,499} & \multicolumn{2}{|c|}{0,653} \\
\hline
\end{tabular}

Tabla 4. Distancias en milímetros entre los ápices radiculares de segundos molares y el piso del seno maxilar y su comparación entre los patrones esqueléticos

\begin{tabular}{lcccccc}
\hline Patrón esquelético & Clase I & Clase II & Clase I & Clase III & Clase II & Clase III \\
\hline Media & 0,437 & & 0,407 & 0,437 & 1,068 & 1,068 \\
Desviación estándar & 1,857 & & 1,672 & 1,857 & 1,784 & 1,672 \\
Valor de t & & 0,059 & & $-1,202$ & $-1,326$ & 0,194 \\
Valor de p & & 0,952 & & & 0,235 & \\
\hline
\end{tabular}

estadísticamente significativas en el segundo premolar entre los patrones de Clase II y III, encontrándose la mayor distancia en los últimos (Tabla 2).

\section{Discusión}

Nguyen-Lan y Hyo-Sang ${ }^{11}$, al estudiar una población coreana el 2017, no encontraron relación entre la distancia de los ápices radiculares posteriores con el piso del seno maxilar y el patrón esquelético sagital. Es importante señalar que en su estudio reportaron medias negativas para todos los órganos dentarios en los tres patrones esqueléticos, a diferencia del presente estudio donde sólo se obtuvieron medias negativas para el primer molar; es decir, en la población coreana encontraron mayor proximidad de los ápices radiculares con el piso del seno maxilar.

Al-Sultany et al. ${ }^{12}$ el 2018, al estudiar una población iraquí entre los 15 y 28 años, encontraron diferencias significativas para los primeros molares entre los patrones esqueléticos de clase I y III. Es posible observar en 


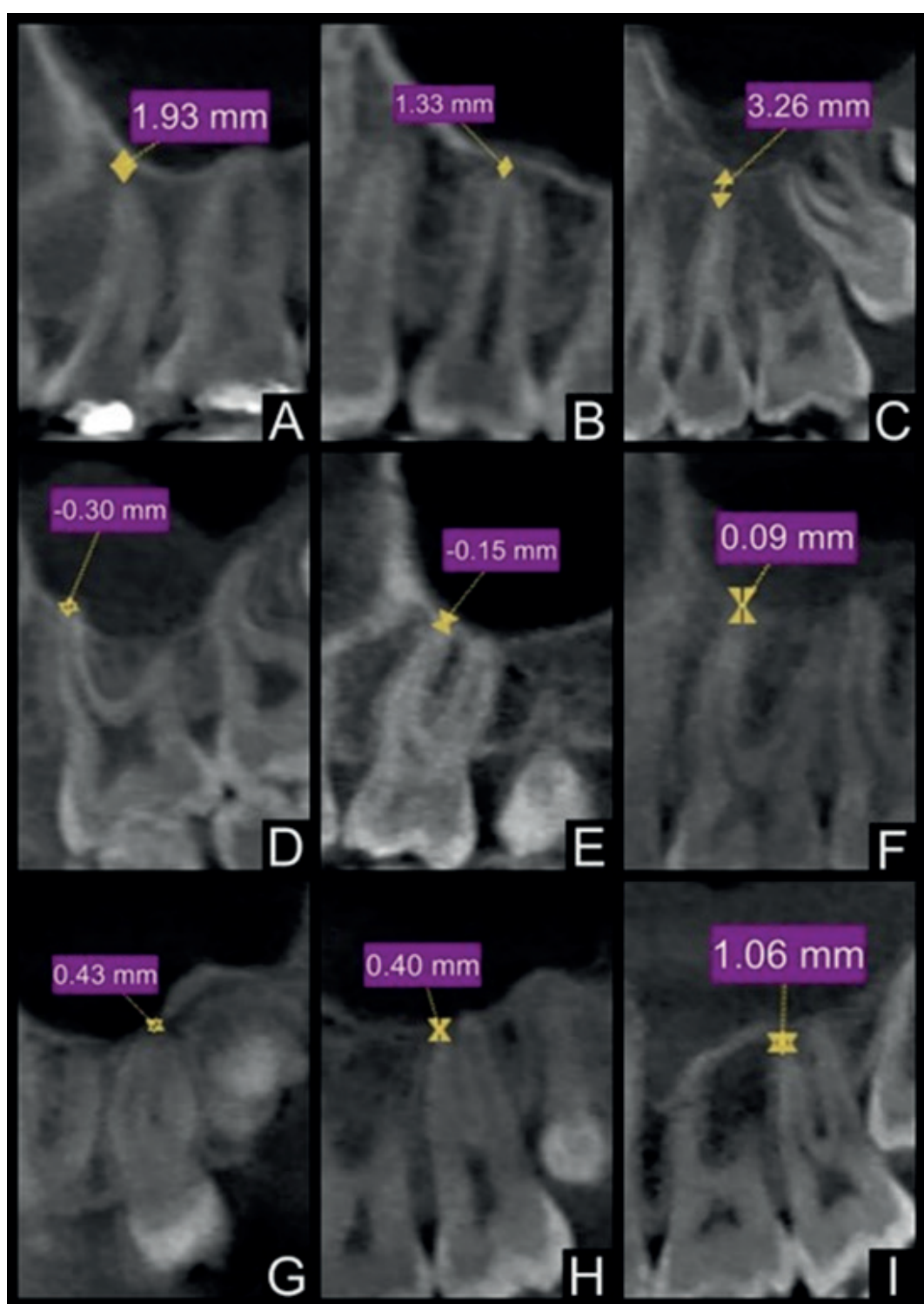

Figura 5. Imágenes de las distancias entre los ápices radiculares y el piso del seno maxilar para cada patrón esquelético (media). A. Segundo premolar, Clase I. B. Segundo premolar, Clase II. C. Segundo premolar, Clase III. D. Primer molar, Clase I. E. Primer molar, Clase II. F. Primer molar, Clase III. G. Segundo molar, Clase I. H. Segundo molar, Clase II. I. Segundo molar, Clase III

sus resultados que las medias obtenidas para los pacientes clase III son las que muestran menor proximidad de los ápices radiculares con el piso del seno maxilar; esta misma característica también fue encontrada en una investigación realizada en la Universidad Mayor de San Marcos, por Ríos Wong L. ${ }^{13}$ y en el presente estudio.

Son pocos los estudios que relacionan la distancia existente entre los ápices radiculares y el seno maxilar con el patrón esquelético sagital. Existen reportes en donde se ha buscado la relación de esta proximidad con el biotipo facial ${ }^{14} \mathrm{y}$ con la mordida abierta ${ }^{15}$ pero no encontraron diferencias significativas entre los grupos estudiados.

El movimiento de los dientes a través del seno maxilar se considera una situación desafiante en ortodoncia, ya que requiere una nueva aposición compensatoria del hueso antes de la resorción ósea en la dirección del movimiento del diente, esto permite mantener la integridad del piso sinusal ${ }^{16}$.
Es sabido que durante el movimiento ortodóntico se produce cierto grado de remodelación radicular que generalmente incluye la formación de cemento nuevo, a menos que esta reabsorción sea muy extensa. En un estudio experimental realizado por Daimaruya et al. ${ }^{17}$ en el que se intruyeron premolares maxilares en el piso de la cavidad nasal se observó reabsorción de leve a moderada sin aposición de cemento reparador, sugiriendo con estos hallazgos que la formación de este cemento podría ser inhibida debido a la fuerza de compresión generada por la membrana nasal bajo la carga de la fuerza ortodóntica.

Diversos autores han reportado que, tanto los movimientos intrusivos como los realizados para el cierre de espacios en ortodoncia a través del seno maxilar, son posibles, siempre y cuando se tenga en cuenta que los grados de reabsorción e inclinación radicular pueden ser mayores que en aquellos casos que no está involucrada esta estructura anatómica ${ }^{4,6,16,17}$. 
Los resultados obtenidos en este estudio mostraron que el patrón esquelético no fue determinante en la distancia de los ápices radiculares de molares superiores al piso del seno maxilar, sin embargo las diferencias encontradas entre los segundos premolares de Clase II y Clase III sí pudieran deberse a esta variable.

La cercanía de los ápices radiculares de premolares y molares superiores al seno maxilar es de gran relevancia para el establecimiento del plan de tratamiento ortodóntico y la toma de medidas precautorias en las mecánicas a realizar durante éste.

Se recomienda que, en los casos que la biomecánica a utilizar lo requiera, se lleve a cabo la estimación de la distancia del piso del seno maxilar a los ápices radiculares posteriores de forma individualizada y a través de medios diagnósticos precisos, como la tomografía de haz cónico.

\section{Referencias bibliográficas}

1. Pinares Toledo J, Carrillo Porras T, Guzmán Zuluaga IC, Ardila Medina CM, Guzmán Zuluaga CL. Variabilidad anatómica de los senos maxilares y de estructuras involucradas en su vía de drenaje. Av Odontoestomatol. 2012;28(2):89-94.

2. Ahn N, Park H. Differences in distances between maxillary posterior root apices and the sinus floor to skeletal pattern. Am J Orthod Dentofac Orthop. 2017;152(6):811-9.

3. Delgadillo J. Crecimiento y desarrollo del seno maxilar y su relación con las raíces dentarias. KIRU. 2005;2(1):4651.

4. Sun W, Xia K, Huang X, Cen X, Liu Q, Liu J. Knowledge of orthodontic tooth movement through the maxillary sinus: a systematic review. BMC Oral Health. 2018;18(1):91.

5. Kosumarl W, Patanaporn V, Jotikasthira D, Janhom A. Distances from the root apices of posterior teeth to the maxillary sinus and mandibular canal in patients with skeletal open bite: A cone-beam computed tomography study. Imaging Sci Dent. 2017;47:157-64.

6. Hyun J, Tai K, Kanao A, Takagi M. Space closure in the maxillary posterior area through the maxillary sinus. Am J Orthod Dentofac Orthop. 2014;145(1):95-102.

7. Hassan BA. Reliability of periapical radiographs and orthopantomogramsin detection of tooth root protrusion in the maxillary sinus:correlation results with cone beam computed tomography. J Oral Maxillofac Res. 2010;1(1):e6.
8. Sharan A, Madjar D. Correlation between maxillary sinus foor topography and related root position of posterior teeth using panoramic and cross-sectional computed tomography imaging. Oral Surg Oral Med Oral Pathol Oral Radiol Endod. 2006;102(3):375-81.

9. Oktay H. The study of the maxillary sinus áreas in different orthodontic malocclusions. Am J Orthod Dentofac Orthop. 1992;102(2):143-5.

10. Emami A, Yasaei S, Mirbeigi S. Cephalometric association of mandibular size/length to the Surface area and dimensions of the frontal and maxillary sinuses. European Journal of Dentistry. 2018;12(2):253-261.

11. Nguyen-Lan, Hyo Sang. Differences in distances between maxillary posterior root apices and the sinus floor according to skeletal pattern. Am J Orthod Dentofac Orthop. 2017;152(6):811-19.

12. Al-sultany $\mathrm{KH}, \mathrm{Al} \mathrm{II}, \mathrm{Sc} \mathrm{M}$. The relation of maxillary root apices and the maxillary sinus floor among patients with different skeletal patterns in Iraqi samples. J Baghdad Coll Dent. 2018;30(4):1-10.

13. Ríos Wong L. Relaciones de los dientes postero superiores y el antro de Highmore según patrón de crecimiento cráneo facial. [Tesis para obtener el título de Cirujano Dentista]. [Lima]: Facultad de odontología, Universidad Nacional Mayor de San Marcos; 2017. 79 p.

14. Costea MC, Bondor CI, Muntean A, Badea M, Mesaroş AŞ, Kuijpers-Jagtman AM. Proximity of the roots of posterior teeth to the maxillary sinus in different facial biotypes. Am J Orthod Dentofac Orthop. 2018;154(3):346-55.

15. Kosumarl W, Patanaporn V, Jotikasthira D, Janhom A. Distances from the root apices of posterior teeth to the maxillary sinus and mandibular canal in patients with skeletal open bite: A cone-beam computed tomography study. Imaging Sci Dent. 2017;47:157-164.

16. Oh H, Herchold K, Hannon S, Heetland K, Ashraf G, Nguyen V, Cho H. Orthodontic tooth movement through the maxillary sinus in an adult with multiple missing teeth. Am J Orthod Dentofac Orthop. 2014;146:493505.

17. Daimaruya T, Takahashi I, Nagasaka H, Umemori M, Sugawara J, Mitani H. Effects of maxillary molar intrusión on the nasal floor and tooth root using the skeletal anchorage system in dog. Angle Orthod. 2003;73(2):158-66. 